\title{
DEVELOPMENT OF VTOL UAV WITH MODULE FOR DIRECTION FINDING
}

\section{KYOUNG-MOO MIN ${ }^{1}$, FOONG-YI CHIA ${ }^{2} \&$ BONG-HWAN KIM ${ }^{3}$}

${ }^{1}$ Graduate School, Department of Automotive Engineering,

Gyeongnam National University of Science and Technology, Jinju, Korea

${ }^{2} R \& D$ Center, SAMCO, Sacheon, Korea

${ }^{3}$ Department of Automotive Engineering, Gyeongnam National University of Science and Technology, Jinju, Korea

ABSTRACT
This paper discusses the design, fabrication and flight test of a vertical take-off and landing aircraft equipped
with a module capable of detecting the position of GPS disturbance signal (jamming signal)when such signal is detected.
During the initial shape design, an estimation of the aircraft weight was first made based on the aircraft components and
the bill of materials (BOM) of the aircraft. After reflecting the weight of all the components in the design, the shape
design of the main wing was performed, followed by center of gravity and neutral point estimation, and propulsion system
design. We have fabricated a UAV that can actually takeoff and land vertically and checked its flight performance
through real flight tests. An aerodynamic analysis is performed using XFLR5. The E-107 and NACA0012 airfoils were
selected as the airfoils for the main wing and tail wings, respectively, and it is designed as H-Tail type for good structural
strength. The quad-copter is arranged such that the center of gravity (CG) of the quad-copter motors passes through the
neutral point (NP) of the aircraft.
KEYWORDS: VTOL UAV, XFLR5, Airfoil, Anti Jamming, Flight Test \& Quad-Copter

Received: Mar 08, 2019; Accepted: Mar 28, 2019; Published: Apr 19, 2019; Paper Id.: IJMPERDJUN201939

\section{INTRODUCTION}

The aim of this research is to develop an unmanned aerial vehicle (UAV) capable of vertical take-off and landing (VTOL) for the purpose of mounting a module capable of detecting the position of GPS disturbance signal (jamming signal)when such signal is detected. In the military boundary area of Korea, there are ten ground facilities to detect disturbing radio signals. However, if disturbance signals are generated behind mountainous terrains, these ground facilities are not capable of direction finding. In order to solve this problem, a direction detection and anti-jamming module are installed on a UAV to locate disturbance signals transmitted from remote places at an altitude of $1 \mathrm{~km}$. The direction finding and anti-jamming module weigh about $2.5 \mathrm{~kg}$ and it has a direction finding antenna at the top and an anti-jamming antenna at the bottom. The basic design of the UAV was developed considering the required space and performance of the aircraft for easy mounting of the module $[1,2,3,4]$.

During the initial shape design, an estimation of the aircraft weight was first made-based on the aircraft components and the bill of materials (BOM) of the aircraft. After reflecting the weight of all the components in the design, the shape design of the main wing was then performed, followed by center of gravity and neutral point estimation, and propulsion system design [4,5,6]. Finally, unmanned vertical take-off and landing aircraft was manufactured and its performance was confirmed through flight tests. Figure 1 and Figure 2 show the initial shape 
of the VTOL UAV capable of being equipped with anti-jamming and direction finding module.

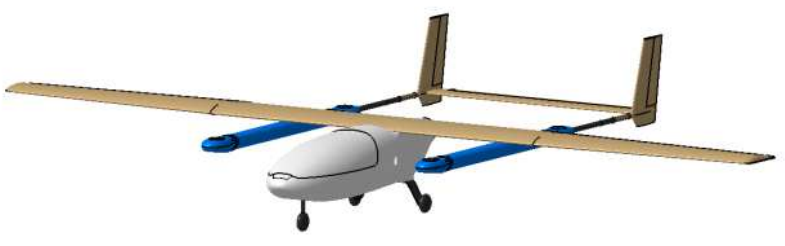

Figure 1: Isometric Shaded Drawing

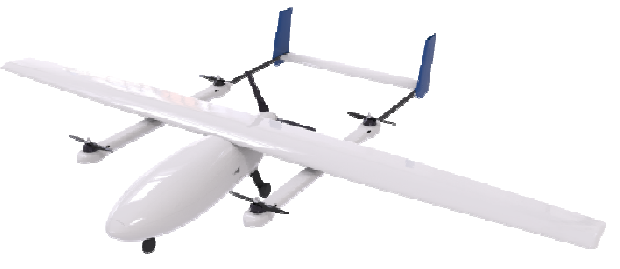

Figure 2 : 3D Rendering View

\section{BASIC DESIGN OF THE AIRFRAME}

\section{Airfoil Selection}

The airfoil selection is very important for the successful flight of an aircraft. The most stable airfoil can be found from research. The airfoil for this aircraft is selected by choosing the airfoil with the highest lift value at the calculated Reynolds Number (Re). The Reynolds number is calculated with the equation below.

$$
R e=\frac{V L}{v}
$$

Re is calculated to be 624,497 when cruise speed, $\mathrm{V}$ is $28 \mathrm{~m} / \mathrm{s}$, mean aerodynamic chord, MAC is $0.264 \mathrm{~m}$, and air kinematic viscosity, $v$ is $1.45^{*} 10^{-5} \mathrm{~m}^{2} / \mathrm{s}$.

Four airfoils with high lift characteristics are selected and aerodynamic analysis was performed using XFLR5[7] at $\operatorname{Re}=624,500$. Figure 3 shows the profiles of the four airfoil selections while Figure 4 shows the results of the analysis. Figure 4 (a) shows that E-197 airfoil provides the highest lift and demonstrates smooth stall characteristics. As shown in Figure4 (b), the E-197 airfoil provides the highest lift per drag compared to other airfoil candidates. Figure 4 (c) shows that the drag coefficient values at low angle-of-attack (AOA) are almost identical for all the airfoils. Based on the analysis results, E-197 was selected as the airfoil of the main wing. Since NACA 0012 is symmetric and has slightly better performance than NACA 0015, NACA 0012 was chosen as the airfoil of the tail wings.

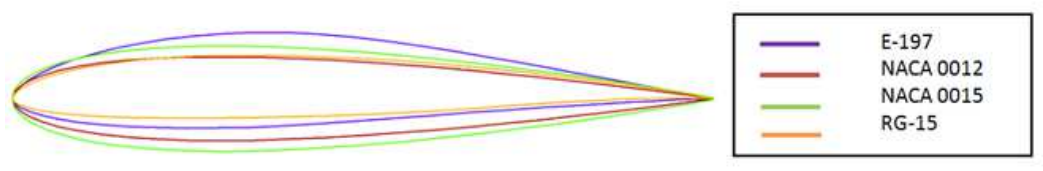

Figure 3: Airfoil Profiles

\section{Wing and Platform Design}

The maximum weight of the unmanned aircraft is estimated to be $23.5 \mathrm{~kg}$ and the lift (L) value is equal to the weight of the aircraft during horizontal flight condition. Therefore, the area of the wing can be calculated eqn. (2) as shown below. 


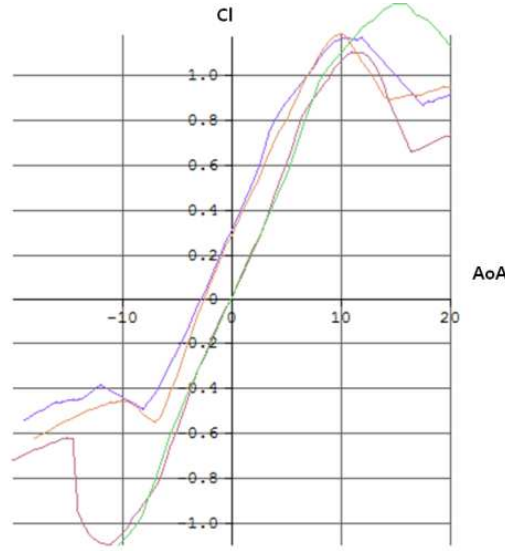

(a) Cl vs. AoA

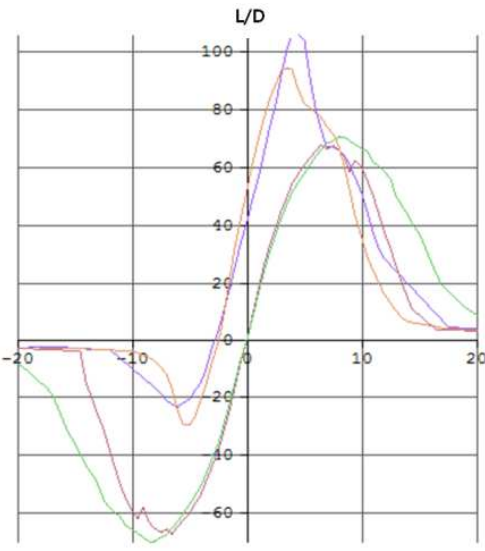

(b) L/D vs. AoA

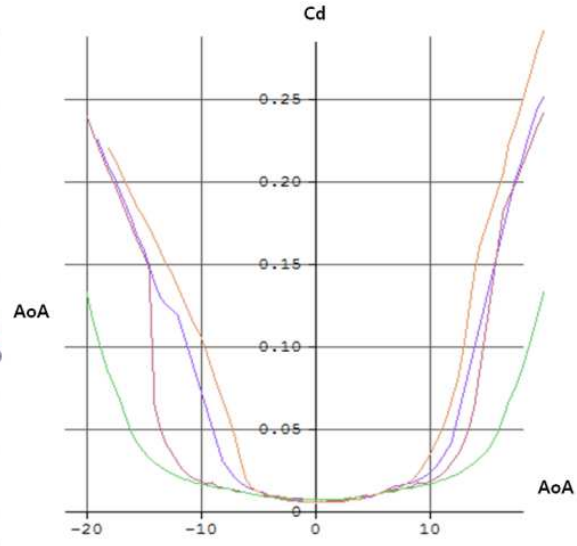

(c) Cd vs. AoA

Figure 4: Lift, Drag and Pitching Moment Coefficients with AoA

$$
L=\mathrm{W}=\frac{1}{2} \rho V_{\text {cruise }}{ }^{2} S_{\text {wing }} C_{L}
$$

As the unmanned aircraft to be developed is a low-altitude aircraft, the sea-level air density $\left(1.225 \mathrm{~kg} / \mathrm{m}^{3}\right)$ is assumed and the cruise speed $\left(V_{\text {cruise }}\right)$ is $28 \mathrm{~m} / \mathrm{s}$, the required lift coefficient, $C_{L}=0.6$ is calculated. As a result of the calculation, the minimum size of the wing area $\left(S_{\text {wing }}\right)$ is $0.8 \mathrm{~m}^{2}$. The size of the tail wing was determined by calculating the required size of the vertical tail and the horizontal tail to meet the target tail volume coefficients[8]. The target vertical tail volume coefficient is 0.5 and the target horizontal tail volume coefficient is 0.04 . The vertical tail volume coefficient was calculated as 0.594, and the Horizontal Tail Volume Coefficient was calculated as 0.0383. The vertical tail volume coefficient was calculated using eqn. (3) below.

$$
\mathrm{Vv}=\frac{\mathrm{Sv} * \mathrm{Lv}}{\mathrm{Sw} * \mathrm{MAC} * \cos ^{2} \phi}
$$

Horizontal Tail Coefficient is calculated with eqn. (4) as shown below.

$$
V_{H}=\frac{S_{H} * L_{H}}{\mathrm{Sw} * \mathrm{MAC}}
$$

The specifications of the wings determined through calculations are shown in Table 1 . Figure 5 shows the shape and size of the platform and wing design of the UAV.

\section{Table 1: Specifications of the Wings}

\begin{tabular}{|l|}
\hline Wing Area, $\mathrm{Sw}=0.83 \mathrm{~m}^{2}$ \\
\hline Wing Span, $\mathrm{b}=3.2 \mathrm{~m}$ \\
\hline Mean Aerodynamic Chord, MAC $=0.264 \mathrm{~m}$ \\
\hline Aspect Ratio, $\mathrm{AR}=12.3$ \\
\hline Wing Incidence $=1^{\circ}$ \\
\hline Wing Dihedral $=0^{\circ}$ \\
\hline Aircraft MTOW $=23.5 \mathrm{~kg}$ \\
\hline Main Wing Airfoil $=\mathrm{E}-197$, Tail Airfoil= NACA 0012 \\
\hline
\end{tabular}



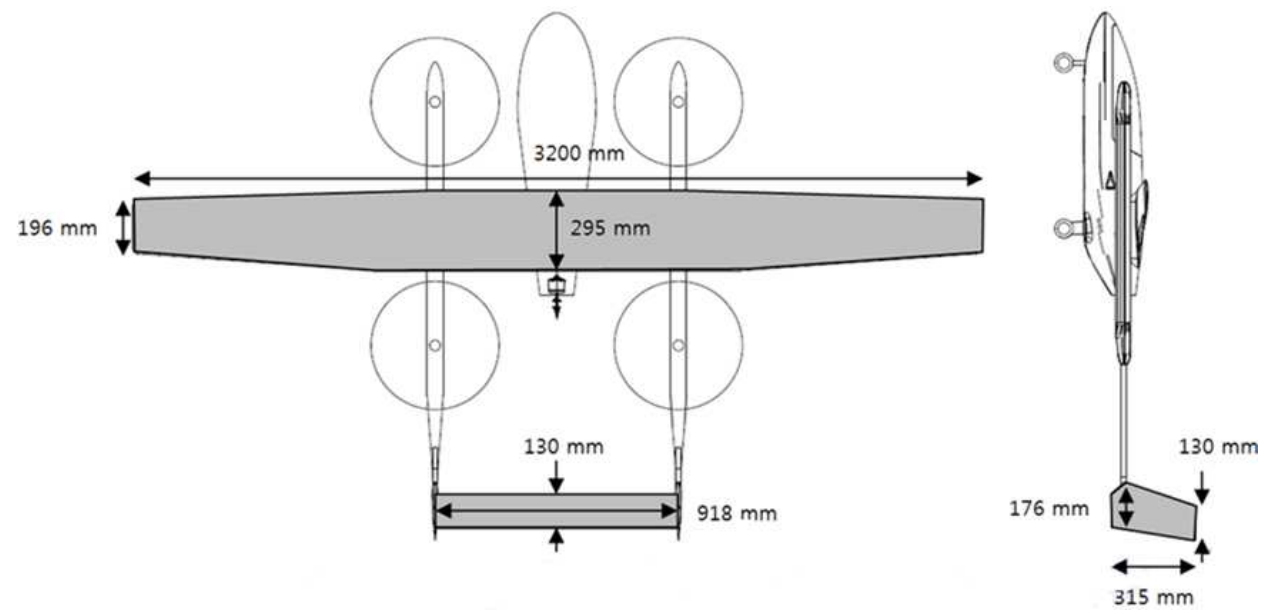

Figure 5: Shape and Dimension of Platform and Wings

\section{Center of Gravity and Neutral Point Estimation}

The aerodynamic effects of the wings and tails of the UAV were calculated through XFLR5 using the Panel Method[7]. The calculation was performed by setting the maximum take-off weight(MTOW) of the aircraft as $23.5 \mathrm{~kg}$ and the cruise speed as $28 \mathrm{~m} / \mathrm{s}$. The simulation was performed to obtain the aircraft's neutral point (NP), and the target center of gravity (CG) was calculated to be at $10 \%$ to $5 \%$ of the static margin (SM). The neutral point (NP) of the aircraft was obtained at $122 \mathrm{~mm}$ and the center of gravity (CG) was calculated to be $100 \mathrm{~mm}$. In order to obtain the Cm vs. AoA graph, the simulation was performed again at the target center of gravity $(\mathrm{CG})$ and the lift value at trim AoA was checked to ensure that lift is sufficient. Figure 6 shows the XFLR5 analysis model, and Figure 7 shows the graphs of the calculation and analysis results.

$$
S M=\frac{X_{N P}-L_{C G}}{\mathrm{MAC}}
$$

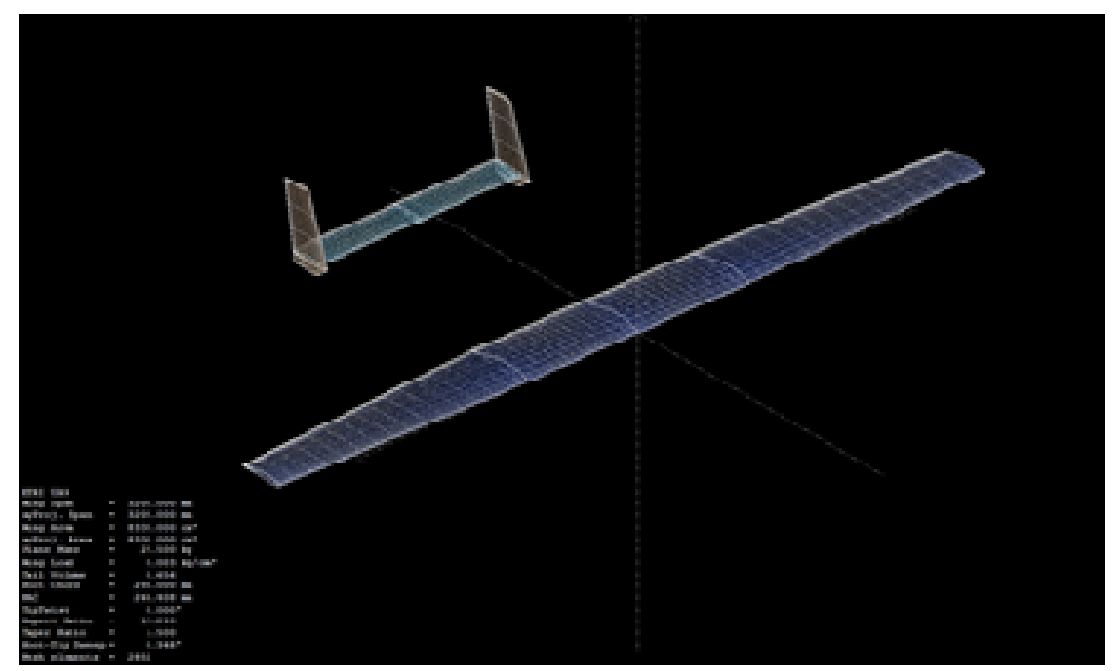

Figure 6: Simulation Model of the Platform by Using XFLR5 


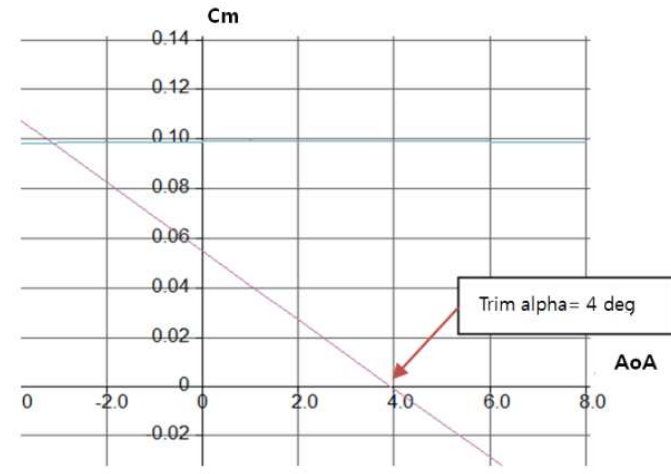

(a) Cm vs. AoA

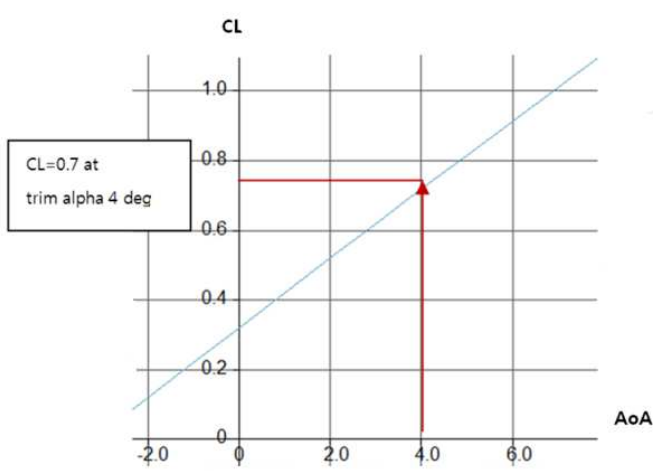

(c)CL vs. AoA

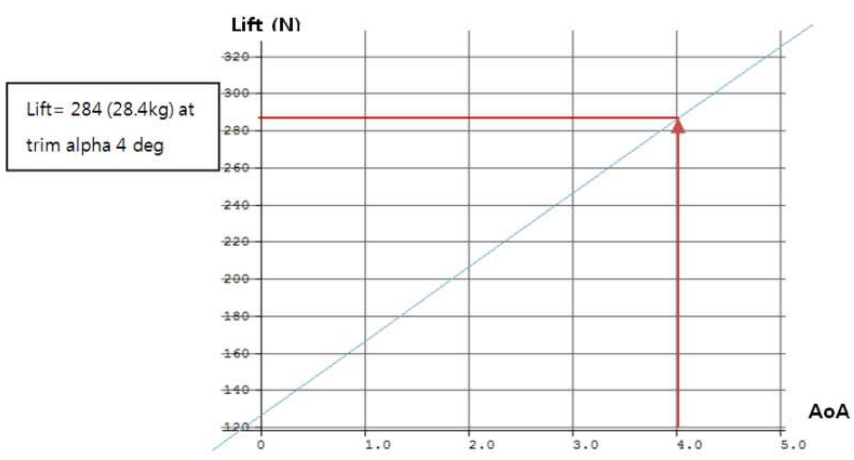

(b) Lift vs. AoA

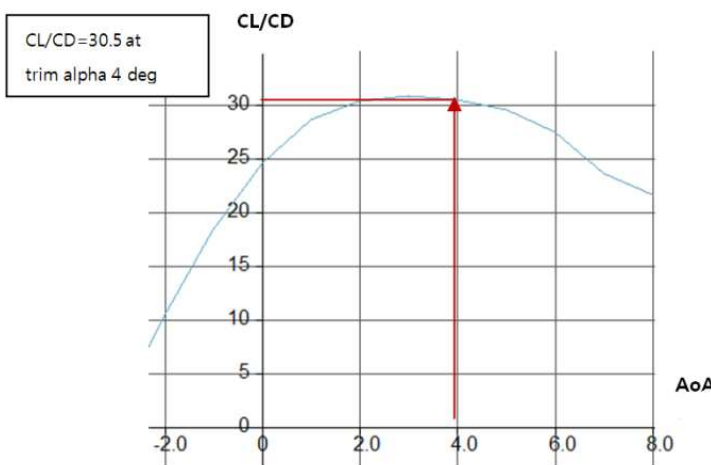

(d)CL/CD vs. AoA

Figure 7: Simulation Results Obtained from XFLR5

The center of gravity estimation was performed using CATIA by modeling each payload component and inputting actual weight data to them. The payload components were arranged to achieve the target center of gravity (CG) of $100 \mathrm{~mm}$. Figure 8 shows the center of gravity (CG) calculated by CATIA and the placement of the components.

\begin{tabular}{|c|c|c|c|}
\hline \multicolumn{4}{|l|}{ Result } \\
\hline \multicolumn{4}{|c|}{ Calculation mode: Approximate } \\
\hline \multicolumn{4}{|c|}{ Type: Volume } \\
\hline \multicolumn{2}{|c|}{ Characteristics } & \multicolumn{2}{|c|}{ Center Of Gravity (G) } \\
\hline Volume & $0.005 \mathrm{~m} 3$ & & $100.995 \mathrm{~mm}$ \\
\hline Area & $1.011 \mathrm{~m} 2$ & Gy & $297.134 \mathrm{~mm}$ \\
\hline Mass & $23155.406 \mathrm{~g}$ & $\mathrm{Gz}$ & $155.575 \mathrm{~mm}$ \\
\hline Density & 4631.081 kg_m3 & & \\
\hline
\end{tabular}

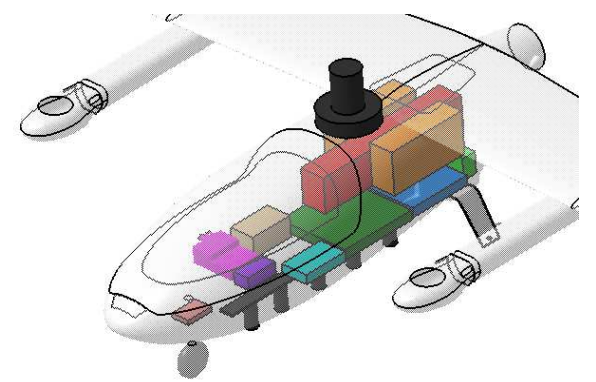

Figure 8: Center of Gravity (CG) Estimation and Arrangement of Payload Components

\section{PROPULSION SYSTEM DESIGN}

The motor and propeller were selected so that the thrust to weight ratio of the forward thrust motor was 2 . The propeller is selected through thrust test by choosing a propeller with a maximum thrust of exceeding $6 \mathrm{~kg}$ when a $12 \mathrm{~S}$ battery is used. We selected the propeller with a thrust above $6 \mathrm{~kg}$ as a candidate through the ground thrust test and made the final selection after checking the acceleration performance, efficiency and airframe vibration characteristics of the propulsion system at the different RPM and airflow effects through actual flight test. The electronic speed controller (ESC) with the capacity of $100 \mathrm{~A}$ is selected considering the capacity safety margin. The vertical take-off motor is selected by 
choosing a motor capable of hovering at below $70 \%$ of its maximum thrust.

In order to select the propeller, the motor thrust test was performed as shown in Table 2 and Table 3, and the candidate propeller was confirmed based on the test data. The final selection of propeller was made through flight test. The $17 \times 13$ propeller was chosen as the propeller for forwarding thrust and the $21.5 \times 7.2$ propeller was selected as the propeller for vertical takeoff and landing as they show the best thrust and efficiency at the same size.

The arrangement of the quad-copter was such that the center of gravity (CG) of the quad-copter motor passes through the neutral point (NP) of the aircraft. The aircraft's CG is positioned at 100mm from the leading edge of the main wing during forwarding flight, and the center of the quad-copter motors for vertical take-off and landing is located $22 \mathrm{~mm}$ aft the CG which is at $122 \mathrm{~mm}$ from the leading edge. The quad-copter motors were arranged at a distance of $918 \mathrm{~mm}$ from each other in the $\mathrm{X}$-axis and $\mathrm{Y}$-axis and the optimal configuration was made such that there will not be a collision between the forward propeller and the vertical propeller. Figure 9 shows the quad-copter arrangement.

Table 2: Test Results of Forward Thrust Motor

\begin{tabular}{|l|c|c|}
\hline \multicolumn{2}{|c|}{ A60-16L/Flame HV 100A/12S 16,000 mAh } \\
\hline \multicolumn{1}{|c|}{ Propeller } & Thrust (kg) & Amp (A) \\
\hline MEJZLIK 16x12 & 6.5 & 54 \\
\hline MEJZLIK 16x14 & 6.5 & 62.3 \\
\hline MENZS 16x12 & 7.3 & 51.4 \\
\hline APC 16x12 & 7.5 & 53.4 \\
\hline APC 16x14 & 6.7 & 45 \\
\hline APC 17x13 & 9.0 & 46 \\
\hline
\end{tabular}

Table 3: Test Results of Vertical Thrust Motor

\begin{tabular}{|c|c|c|}
\hline Propeller & Thrust (kg) & Amp (A) \\
\hline KDE 21.5x7.2 & 10.6 & 62.5 \\
\hline T-MOTOR 21x6.3 & .6 & 48 \\
\hline
\end{tabular}

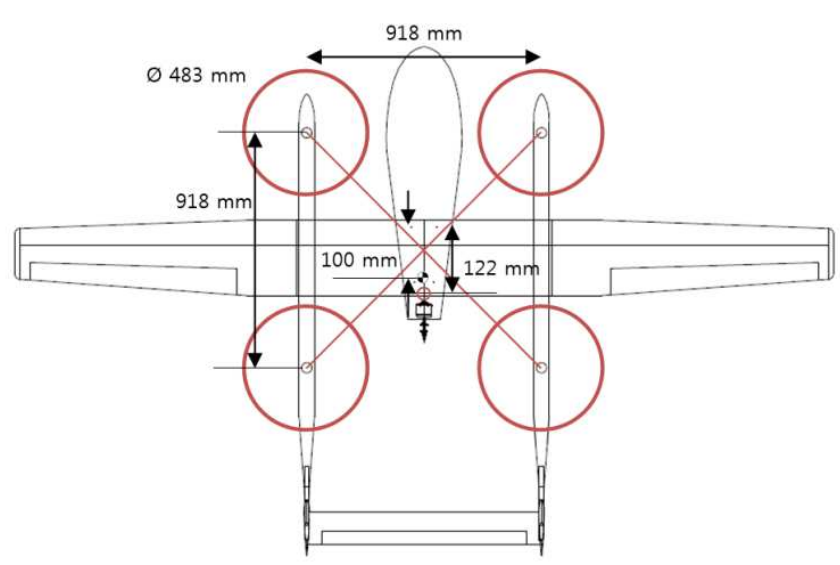

Figure 9: Arrangement of the Quad-Copter

\section{MANUFACTURE OF AIRFRAME}

The first prototype of the airframe was produced during the PDR (Preliminary Design Review) and Critical Design Review (CDR) stage and there were problems with the flight performance during the initial flight. The problems were resolved by changing the configuration of the tail wing. Figure 10 shows a picture of the airframe produced. The configuration of the tail was changed from inverted V-tail design to H-tail design so that it is structurally stronger. 
The airfoil and wing area were also changed to obtain a higher lift coefficient. Also, the position of the pitot-tube was changed due to reading errors which occurred due to vortex generation at the nose portion of the fuselage.

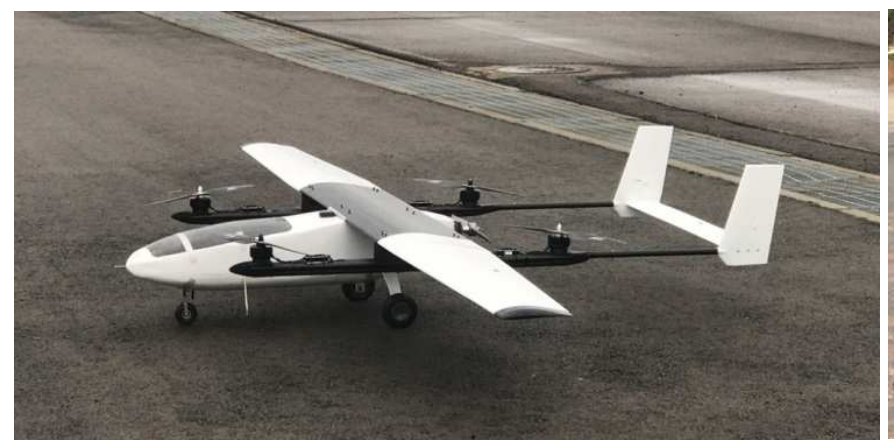

Figure 10: Manufactured Airframe

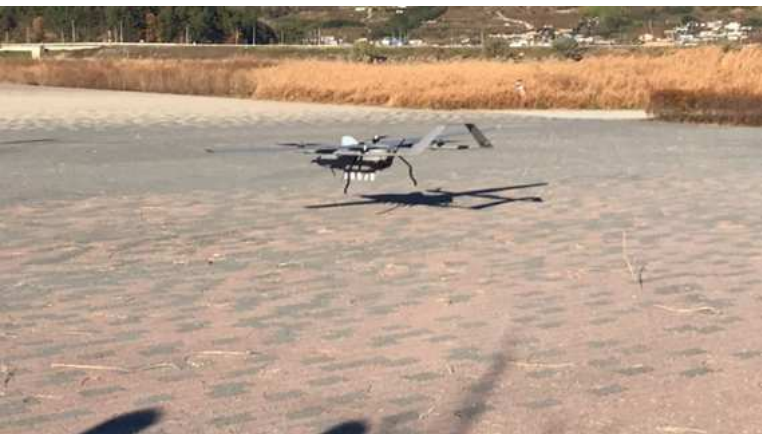

Figure 11:Take-Off Scene of the GPS Direction Finding Test

\section{FLIGHT TEST DATA}

During the GPS direction finding test, the flight test was performed at different altitudes as there was difficulty performing the tests at long distances [9]. Figure 11 shows the take-off scene of the GPS direction finding flight test. Flight test data were logged and shown in Figure 12 to Figure 15. The flight test was performed by sending regular pitch up/down commands, generating pitch angles of the UAV in the range of -10 to +10 degrees. The flight altitude was maintained at $20 \mathrm{~m}$ and the flight velocity was between $2 \sim 4 \mathrm{~m} / \mathrm{s}$ throughout the flight tests. It is confirmed that the unmanned airplane responded very well to the flight commands. Figure 12, 13, and 14 show the ability of the UAV to follow altitude, attitude, and velocity commands, respectively. Figure 15 shows a three-dimensional (3D) flight path.

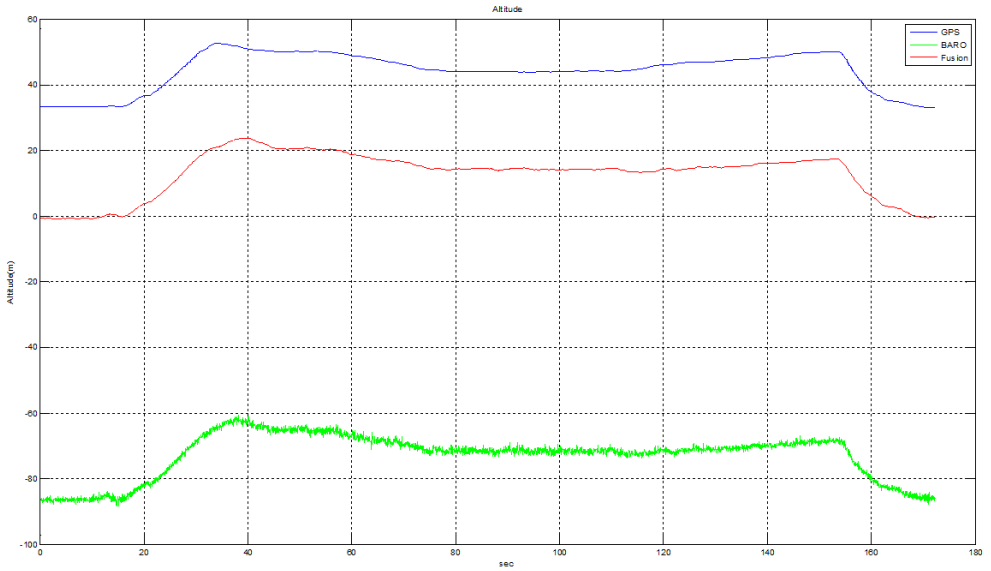

Figure 12: Flight Altitude Graph 

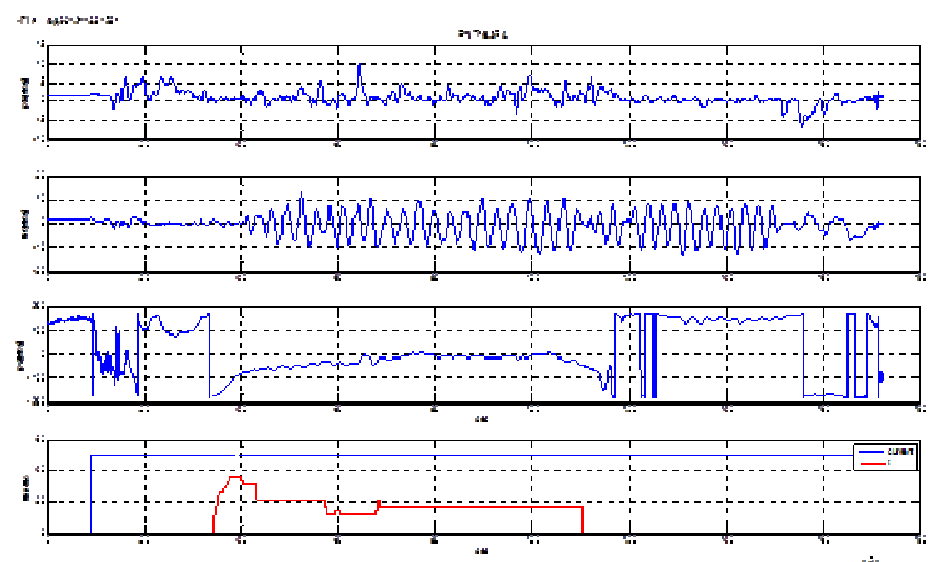

Figure 13: Flight Attitude Graph

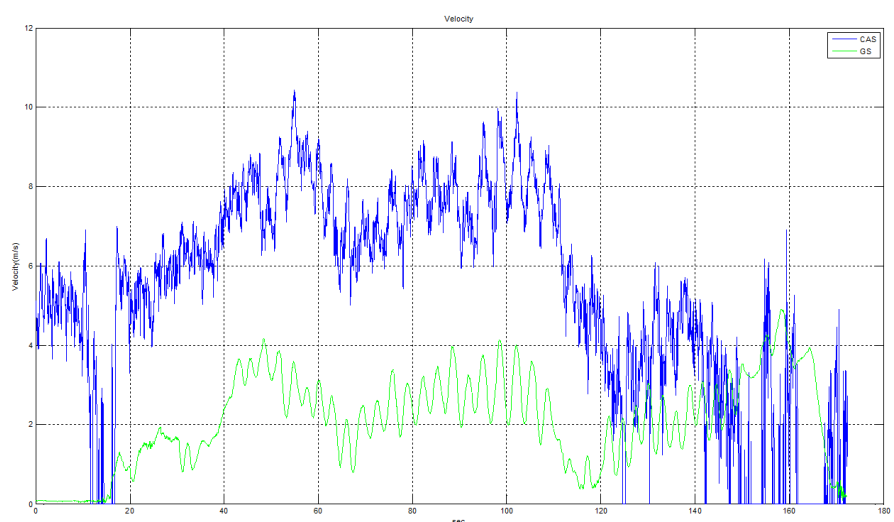

Figure 14: Flight Velocity Graph

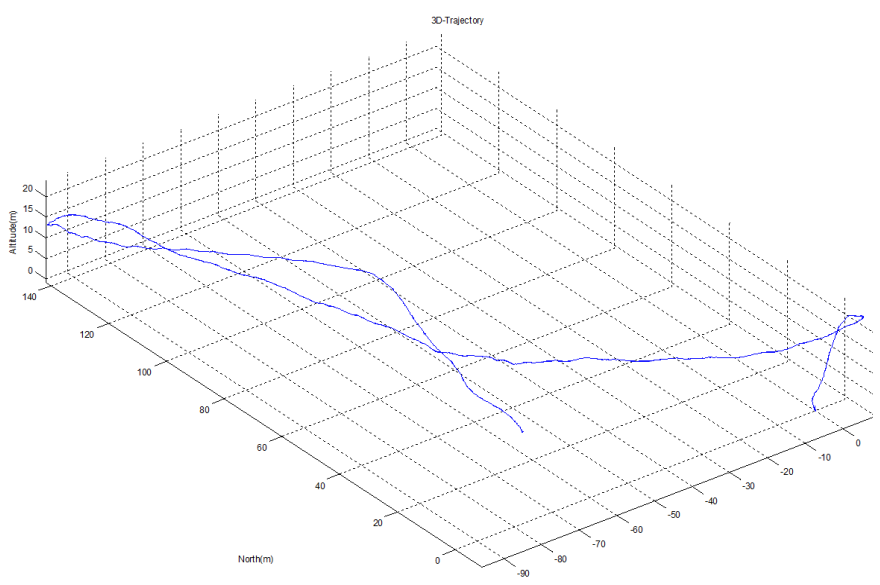

Figure 15 : 3D Trajectory Flight Path

\section{CONCLUSIONS}

The main purpose of this project is to determine the optimal airframe of a UAV to be equipped with a module capable of detecting the position of the GPS disturbance signal (jamming signal) when such signal is detected. In this study, XFLR5 was used for aerodynamic design and E-197 was selected as the main airfoil based on the analysis results. A symmetrical airfoil, NACA 0012 was chosen as the airfoil of the tail wing and the H-tail configuration was selected to enhance structural strength. The arrangement of the quad-copter is such that the center of gravity (CG) of the quad-copter 
motor passes through the NP of the aircraft. The aircraft's CG is positioned $100 \mathrm{~mm}$ from the leading edge of the main wing during forwarding flight, and quad-copter motor center is located at $122 \mathrm{~mm}$, which is $22 \mathrm{~mm}$ aft of the CG. The quad-copter motors were arranged at a distance of $918 \mathrm{~mm}$ from each other in the X-axis and Y-axis and the optimal configuration was made such that there will not be a collision between the forward propeller and the vertical propeller. It confirmed through flight test that the unmanned aircraft responses very well to flight commands.

\section{REFERENCES}

1. Anderson, John D., 1999, "Aircraft Performance and Design", McGraw-Hill.

2. S. Verling, J. Zilly, 2013, "Modeling and Control of a VTOL Glider", Bachelor thesis, ETH, Zurich.

3. Ozdemir, U. et al, 2014, "Design of a Commercial Hybrid VTOL UAV System, Journal of Intelligent and Robotic Systems", 74(1-2), pp. 371-393.

4. K.M. Min, F. Y. Chia and B. H. Kimn, 2019, "Design \&CFD Analysis of a Low-Altitude VTOL UAV", International Journal of Mechanical and Production Engineering Research and Development,Vol.9, Issue 2, pp.541-548.

5. Armutcuoglu, O., 2000, "The Conceptual Design Of a Tilt-Duct VTOL UAV", M.Sc. Thesis, Middle East Technical University.

6. Yun, K., Hirano, M., Yanase, S., \& Ohya, Y. (2016). New Fabrication Method Suggestion of the Motor Core Using Ceramic Precursor. International Journal of Metallurgical \& Materials Science and Engineering (IJMMSE) ISSN (P), 2278-2516.

7. Theresa Shafer et al., 2014, AIAA SciTech, "Comparison of Computational Approaches for Rapid Aerodynamic Assessment of Small UAVs", http://arc.aiaa.org/doi/abs/10.2514/6.2014-0039

8. XFLR5: http://www.xflr5.com/xflr5.htm

9. Sravan Kumar Khuntia, Amandeep Singh Ahuja, 2018, "Optimumal Design and CFD Analysis of Wing of a Small-scale UAV to Obtain Maximum Efficiency", International Journal of Computer Application(2250-1797) Issue 8 Volume 1.

10. K.M. Min, F. Y. Chia and B. H. Kimn, 2019, "Design \& Flight Test Result of a Small Scale Hybrid VTOL UAV", International Journal of Mechanical and Production Engineering Research and Development, Vol.9, Issue 2, pp.203-210.

11. Surve, B., Kelotra, A., \& Despande, M. Location base-Monthwise Estimation of PV Module Power Output by Using Neural Network which Operates on Spatio-Temporal Gis Data. 
